\title{
Defining a US Architecture for Environmental Monitoring from Space
}

\author{
Zoe Szajnfarber, ${ }^{\mathrm{i}}$ Thomas G. Beatty, ${ }^{\mathrm{ii}}$ Matthew W. Petersen, ${ }^{\mathrm{iii}}$ Anna Vasilyeva, ${ }^{\mathrm{iv}}$ D. Brent White ${ }^{\mathrm{v}}$ and Annalisa L. Weigel ${ }^{\mathrm{vi}}$ \\ Massachusetts Institute of Technology, Cambridge, MA, 02139
}

The U.S. lacks a coherent integrated architecture, organization, and strategy for planning capabilities and investments in space-based environmental monitoring. In order to clarify the underlying problem, this paper contributes a new way to conceptualize the capability development process in terms of a two dimensional value stream - within project development and between project developments. Using this framework, the nature of the observed inconsistent service delivery - often attributed to a "gap" in the research to operations handoff - is investigated through an analysis of several historical projects. It is found that the issues are deeper than "poor coordination;" further, that programs do not progress, as expected, from research to operations. Even when the progression is expanded to separate science maturity from technology maturity, many programs experience maturity cycles as major new generations are initiated. By way of solution, four architectural alternatives are proposed and evaluated. However, until a coordinated vision for remote sensing is agreed to, taking steps to refine alter or clarify agency roles may be of limited value.

\section{Introduction}

$T$ HE last five decades have witnessed the growth of space-based Earth monitoring, from the first crude images of the Earth from space taken by Explorer 6 in 1959, to the present sophisticated platforms like GeoEye-1, a commercial asset boasting $41 \mathrm{~cm}$ resolution launched in 2008. ${ }^{1}$ Since the middle of the last century, the scope of remote sensing and the kinds of data have grown as well: from simple optical imagery of the Earth to multispectral imaging, spectroscopy, laser altimetry, and a variety of space weather measurements. The result has been an enormous expansion in our understanding of the Earth's climate, land use, changes, and atmosphere. Indeed, it is easy to forget that the multi-day weather forecasts that we are so used to were impossible until the advent of spacebased environmental monitoring systems.

While these functions of weather monitoring, earth science, and resource management etc, are currently linked by their common reliance on space -based sensors, they otherwise draw on very different sets of expertise. Thus, the multiple different federal agencies, which have historically been individually responsible for a single compartmentalized function within the remote sensing enterprise, must now work together in a coordinated fashion. Broadly speaking, the National Aeronautics and Space Administration (NASA) is concerned with advanced science missions, seeking to answer "big questions" about the earth system; the National Oceanic and Atmospheric Administration (NOAA) focuses on the more routine task of weather forecasting and monitoring; the US Geological Survey (USGS) has extended its resource management function to include the analysis, dissemination and archiving of space-based images of the earth; and the Department of Defense (DoD) uses space-based remote sensing to serve its own national security purposes. However, as the field of space-based remote sensing becomes increasingly integrated and given the significant overlap in space engineering expertise required across each discipline, coordination challenges will only increase.

Part of the problem is that the nature of the coordination challenge is not yet well understood. To address this gap, this paper analyzes the US remote sensing architecture through three complimentary lenses. First it examines

\footnotetext{
${ }^{\mathrm{i}}$ Doctoral Research Assistant, Engineering Systems Division, zszajnfa@mit.edu; 857-233-6091; 77 Massachusetts Ave. Building 17-110; Cambridge MA, 02139, AIAA Student Member

${ }^{\text {ii }}$ Graduate Research Assistant, Department of Physics, tbeatty@space.mit.edu

iii Undergraduate Research Assistant, Department of Aeronautics \& Astronautics, mattwp@mit.edu

${ }^{\text {iv }}$ Graduate Research Assistant, Department of Aeronautics \& Astronautics, annav@mit.edu

${ }^{v}$ Doctoral Research Assistant, Department of Aeronautics \& Astronautics, bjwhite@mit.edu

${ }^{v i}$ Assistant Professor of Aeronautics and Astronautics and Engineering Systems, alweigel@mit.edu, AIAA Associate Fellow
} 
the components of the system - the individual organizations and the regulations and laws that govern their interaction - in order to understand the extent and nature of overlapping roles and responsibilities. Second, it takes a process view, examining how, and the extent to which, the value generating functions are contingent on each other. Third, selections of historical programs are examined in order to understand trends in system evolution. Based on these three analyses, the nature of the challenges facing the US remote sensing architecture are characterized and used to assess potential reorganization pathways.

\section{Components of the Remote Sensing Architecture: Over- and "Under"-lapping Responsibilities}

The US remote sensing system is a system of organizations which themselves, design, develop, launch, operate and use, satellite systems. For the sake of consistency, in the remainder of this paper "the system" will refer to 1) the set of organizations that interact to generate information useful in understanding the state - past present and future of the earth (including land, sea and atmosphere) and space environment; and 2) the rules (be they formal or conventional) that govern those interactions. The system as a whole delivers value by generating and analyzing data, collected remotely by orbiting satellites. The major organizational stakeholders include the National Aeronautics and Space Administration (NASA), the National Oceanic and Atmospheric Administration (NOAA), the U.S. Geological Survey (USGS), the Department of Defense (DoD), the U.S. Group on Earth Observation (USGEO) and several international coordinating bodies and commercial entities. The rules that govern their interactions are encapsulated in their respective charters, congressional acts and de facto conventions. An overview of the roles, responsibilities and authorities of these stakeholders is provided in Section 0 . Then, in order to further illustrate the complexity of their interactions, the evolution of the Landsat system will be described so as to concretize the discussion.

\section{Stakeholder Descriptions}

This section provides a brief overview of the organizational identities, core competencies, mandates, and budget authorities of each of the key stakeholders in the US Remote Sensing System. The intent is to highlight key tensions and provide a basis for the analysis in the sections that follow. The uninitiated reader is referred to agency websites for further information.

\section{National Aeronautic and Space Administration (NASA)}

The National Aeronautics and Space Administration is an executive agency responsible for conducting the US civil Space Program. With respect to environmental monitoring, NASA's mission is to "develop a scientific understanding of Earth's system and its response to natural or human-induced changes, and to improve prediction of climate, weather, and natural hazards. "2 In practice, this translates to an emphasis on the development of new technologies and approaches in support of advanced science. NASA works closely with Principle Investigators (PIs) for each mission. Over the years, NASA has developed, launched, and operated multiple satellites which have materially improved weather forecasts, provided information tools for agriculture and forestry, and provided a platform for predicting climate change in the future. ${ }^{\text {vii }}$ In addition to the advanced science thrust, NASA also serves as a technical pseudo-subcontractor to NOAA, designing and developing operational remote sensing satellites. It gets its budget authority - approximately $\$ 17.6 \mathrm{~B}$ of which $\$ 4.5 \mathrm{~B}$ is dedicated to remote sensing - appropriated by the subcommittee on VA - HUD and Independent Agencies.

\section{National Oceanic and Atmospheric Administration (NOAA)}

The National Oceanic and Atmospheric Administration is a science-based agency within the Department of Commerce that is tasked with monitoring and providing information on the nation's oceanic and atmospheric environments and resources. As part of the Department of Commerce, NOAA receives its budget - approximately \$1.2B for remote sensing - through the Subcommittee on Commerce, Justice, Science, and Related Agencies. ${ }^{3}$ In terms of space-based environmental monitoring, NOAA is responsible for building ${ }^{\text {viii }}$ and operating operational weather and meteorological satellites. It also distributes and archives the data it collects for use by other government agencies and environmental scientists.

Through the National Environmental Satellite, Data, and Information Service (NESDIS) Office of Satellite Operations, NOAA is responsible for the management of three environmental monitoring programs. The first two,

\footnotetext{
${ }^{\text {vii }}$ http://nasascience.nasa.gov/earth-science/mission_list

viii Although as discussed earlier, without in-house satellite engineering expertise, NOAA uses NASA as a pseudocontractor.
} 
the Geostationary Operational Environmental Satellites (GOES) and Polar Operational Environmental Satellites (POES), are the primary meteorological satellite constellations for the United States. The third constellation that NESDIS operates is the Defense Meteorological Satellite Program (DMSP), which NOAA acquired from the Department of Defense. NESDIS also houses the National Polar-orbiting Operational Environmental Satellite System (NPOESS) Integrated Program Office. NPOESS is a new satellite constellation that is planned to replace the POES and DMSP constellations and combine their capabilities onto a single series of spacecraft. The Integrated Program Office is a tri-agency program that employs NOAA personnel from the DOC, as well as personnel from the DoD and NASA.

\section{United States Geological Survey (USGS)}

The U.S. Geological Survey (USGS) is one of the eight bureaus that make up the Department of the Interior (DOI). ${ }^{4}$ It gets its budget authority - approximately $\$ 73 \mathrm{M}$ for remote sensing - through the Subcommittee on Interior, Environment, and Related Agencies. Within the DOI's broad mission of protecting and managing the Nation's natural resources and cultural heritage, the USGS collects, monitors, analyzes, and provides scientific understanding about natural resource conditions, issues and problems. The agency prides itself on the diversity of its scientific expertise which enable USGS to carry out "large-scale, multi-disciplinary investigations and provide impartial scientific information to resource managers, planners, and other customer." Many of USGS's scientific objectives increasingly require access to, and analysis of, remote sensing data. ${ }^{6}$ As a result, the agency has a long history of maintaining archives from its own mapping projects and from those of some other Federal Agencies. It began using remote sensing data in earnest in the 1930's, using aerial photographs to enhance mapping projects. More recently, USGS's EROS Data Center processes and stores satellite data from several satellites. This archive includes manned spacecraft photographs, ${ }^{\mathrm{ix}}$ Landsat data, ${ }^{\mathrm{x}}$ and data from the Advanced Very High Resolution Radiometer (AVHRR). ${ }^{\mathrm{xi}}$

Although the USGS's expertise in remote sensing has historically been limited to data archiving and analysis, this may soon change. In 2007, the Future of Land Imaging Interagency Working Group, headed by the Office of Science Technology Policy (OSTP) released "A Plan for a U.S. National Land Imaging Program." It proposed that the U.S. establish a "National Land Imaging Program" led by the DOI, specifically USGS. In addition to back-end archiving and analysis, USGS is now responsible for the front-end requirements generation and planning processes. In addition to interfacing with its traditional customers, USGS must coordinate among NASA, NOAA and the National Geospatial Intelligence Agency (NGA). Of the FY2009 Budget request, a \$2,000,000 increase to the remote sensing was approved to establish the National Land Imaging program described above.

\section{United States Department of Agriculture (USDA)}

The United States Department of Agriculture (USDA) is one of the major users of remote sensing data. It includes agencies such as the National Agricultural Statistics Service (NASS) that uses aerial and satellite imagery to analyze crop production and condition, the Forest Service (FS) that uses remote sensing for forest monitoring and to provide geospatial data to meet the needs of disaster responders and researchers, and the Agricultural Research Service (ARS) that through the Hydrology and Remote Sensing Laboratory conducts research on improving remote sensing techniques used by other agencies. Furthermore, along with NOAA, USDA is part of the Joint Agricultural Weather Facility that uses remote sensing data to assess the likely weather impact on crops around the world. To link similar data sets and technologies used by different agencies under the USDA, the Remote Sensing Coordination Committee (RSCC) is set up to "promote information sharing ... and help ensure the most efficient and cost-effective use if these data and technologies".

\footnotetext{
${ }^{i x}$ Photographs were taken over limited areas of the Earth on NASA's Gemini (1965-66) and Apollo (1968-69) Missions. Three Skylab missions in 1973 and 1974 resulted in more than 35,000 photographs. Astronauts aboard the Space Shuttle, which began flying in 1981, have taken many photographs of the Earth with hand-held cameras. These photographs document sites of scientific interest around the world and depict temporary phenomena such as hurricanes and erupting volcanoes. Most are in natural color.

${ }^{x}$ USGS maintains an archive of processed Landsat data, collected since 1972. The data is collected in multiple wavelengths of electromagnetic energy

${ }^{x i}$ This is one of several sensors aboard meteorological satellites operated by NOAA. This data is collected in the visible, near-infrared, and thermal-infrared portions of the electromagnetic spectrum.
} 


\section{Department of Defense (DoD)}

Remote sensing data plays an important role in planning and managing military operations. Although the data required for these purposes shares many of the attributes of other non-military applications (e.g., high resolution ground images, weather forecasts), because of the strategic importance of the information, the DoD has historically designed, developed and operated its own satellites. More recently however, efforts have been made to minimize the duplication of effort. For example, the National Polar-orbiting Operational Environmental Satellite System (NPOESS) and NGA's involvement in the Land Imaging Program, as described above. The DoD has two main remote sensing thrusts (weather and imaging), each under a different office or "three letter agency ${ }^{\mathrm{xii}}$," many of which are highly classified.

The Defense Meteorological Satellite Program is run $^{\text {xiii }}$ by the Air Force Space and Missile Systems Center (SMC) which designs, builds, launches, and maintains satellites monitoring the oceanographic, meteorological and solar-terrestrial physics environments. ${ }^{9}$ The two DMSP satellites are equipped with sensors to monitor both terrestrial weather as well as space weather (i.e., solar flares, noise storms and other releases of energy from the sun). Terrestrial forecasts are used by the military to plan operations. Space forecasts are of interest to both military and civilian stakeholders concerned with space weather, power and communications in countries throughout the world. SMC increasingly collaborates with NOAA on weather issues. ${ }^{8}$ DMSP data is archived by the Earth Observation Group (EOG) at NOAA's National Geophysical Data Center (NGDC). In addition to maintaining the data archive, the EOG processes and performs research on the data. ${ }^{9}$

The National Reconnaissance Office (NRO) builds and operates the nation's reconnaissance satellites. As part of the US Intelligence Community (IC), its mission is to engage "in the research and development, acquisition, launch and operation of overhead reconnaissance systems necessary to meet the needs of the Intelligence Community and of the Department of Defense." ${ }^{\prime 10}$ NRO is jointly staffed by the DoD and CIA. The specifics of NRO activities remain highly classified, although some information about past projects is beginning to be released. Data from NRO satellites is processed and analyzed by the National Geospatial Intelligence Agency (NGA) which is a DoD combat support agency and part of the intelligence community (IC). ${ }^{I I}$

\section{Intergovernmental Group on Earth Observations (GEO)}

The intergovernmental Group on Earth Observations (GEO) is a coordinating body established during the Third Earth Observation Summit in February 2005 to carry out the Global Earth Observation System of Systems (GEOSS) 10-Year Implementation Plan. GEOSS's purpose is "to achieve comprehensive, coordinated and sustained observations of the Earth system, in order to improve monitoring of the state of the Earth, increasing understanding of Earth processes, and enhance prediction of the behavior of the Earth system." ${ }^{2}$ The formation of GEO, and subsequently the development of the 10-Year Implementation Plan, comes from a global recognition of the need to strengthen the coordination of Earth observations, predictions, and data sharing among the global community.

GEO is made up of international governing bodies and regional organizations, including 77 countries, the European Commission, and 56 participating organizations. ${ }^{13}$ GEO oversees the implementation of GEOSS through four committees that support architecture and data management, engage the scientific and technological communities in the purpose of GEOSS, coordinate user interface to ensure continuity and avoid duplication in Earth observation activities, and strengthen countries' capabilities to use Earth observation data. ${ }^{14}$ The four committees aim to construct GEOSS to facilitate the transition from Earth observation programs to global operational use and ensure cooperation between the agencies of member countries and organizations participating in global observing systems. GEOSS projects are funded by member organizations participating in those projects. Special ventures are also funded by voluntary contributions.

The U.S. contribution to GEOSS is the U.S. Integrated Earth Observation System (IOES), which is currently developed and coordinated by U.S. Group on Earth Observation (USGEO). Its function includes performing "an assessment of how to integrate current observational capabilities across scales, and an evaluation of data gaps and research and development needs".xxviii The subcommittee is currently co-chaired by senior officials from NOAA, NASA, and OSTP and includes representatives from member agencies of the Committee on Environment \& Natural Resources as well as other appropriate government entities.

\section{Commercial Space Stakeholders}

The commercial remote sensing industry includes, most prominently, the imagery companies GeoEye, Spot Image, and DigitalGlobe. Small by aerospace standards, the largest of these companies, GeoEye, is worth

\footnotetext{
${ }^{\text {xii }}$ E.g., DIA, NGA, NRO, CIA etc...

xiii NOAA now operates the satellites for SMC
} 
approximately $\$ 1 \mathrm{~B}$ and employs 400 people. In recent years, the commercial remote sensing industry has been driven by growth in the consumer demand for space imagery (e.g., Google Earth), and the relatively recent reorientation of US government agency imaging from government-operated assets to data purchased commercially. The National Geospatial Intelligence Agency (NGA) is one of GeoEye's principle clients, while also letting remote sensing contracts to GeoEye's chief competitor, DigitalGlobe. Spot Image is a French company, with similar contracts in the European community. Google Earth owns exclusive rights to online images from GeoEye's newest satellite, GeoEye-1. In fact, the U.S. government split the development costs of this satellite with Google, and has restricted access to GeoEye-1's highest resolution imagery to itself.

\section{Individual End-Users}

A wide variety of individuals use data provided by the satellites run by NASA, NOAA, and the USGS, as illustrated in Table 2. Since these groups are so diverse, there is only limited communication between many of them; each group of end users is generally connected with only one of the relevant agencies. For example, most meteorologists work through NOAA, while most planetary scientists work through NASA. As a result, most environmental monitoring missions are proposed and designed by a subset of their potential end-users.

In some cases, this facilitates the planning process. Planetary scientists, for instance, are not reliant on NOAA spacecraft, while the military does not depend on those run by NASA. Civil engineers use USGS Landsat data, while oceanographers have no need to interact with the USGS. However, for most of the users of environmental monitoring data, the overlapping missions and expertise in NASA, NOAA, and the USGS are problematic. Operational users rely on the new instruments developed by the experimentalists, and the experimentalists acquire a sense direction from the needs of the operational users. In Table 2, NOAA programs are highlighted in blue, USGS in green and NASA missions in pink. It can be seen that the majority of users require data from multiple satellites and agencies, indicating that the NASA-NOAA-USGS division of labor is not as clean as one might hope.

Table 1 - Users and Missions

\begin{tabular}{|c|c|c|c|c|c|c|c|c|c|c|}
\hline Users & GOES & NPOESS & Landsat & Aqua & Aura & PARASO & ALIPSO & Cloudsat & Terra & Quickscat \\
\hline Civil Engineers & & & $\mathrm{X}$ & & & & & & & \\
\hline Climatologists & $\mathrm{X}$ & $\mathrm{X}$ & & $\mathrm{X}$ & $\mathrm{X}$ & $\mathrm{X}$ & $\mathrm{X}$ & $\mathrm{X}$ & $\mathrm{X}$ & $\mathrm{X}$ \\
\hline Farmers & $\mathrm{X}$ & $\mathrm{X}$ & $\mathrm{X}$ & $\mathrm{X}$ & & & & & $\mathrm{X}$ & \\
\hline Mariners & $\mathrm{X}$ & $\mathrm{X}$ & & & & & & & & $\mathrm{X}$ \\
\hline Meteorologists & $\mathrm{X}$ & $\mathrm{X}$ & & $\mathrm{X}$ & $\mathrm{X}$ & $\mathrm{X}$ & $\mathrm{X}$ & $\mathrm{X}$ & $\mathrm{X}$ & $\mathrm{X}$ \\
\hline Military & $\bar{X}$ & $\bar{X}$ & $\mathrm{X}$ & & & & & & & $\bar{X}$ \\
\hline Oceanographers & & $\mathrm{X}$ & & $\mathrm{X}$ & & & & & & $\mathrm{X}$ \\
\hline Planetary Scientists & & & $\mathrm{X}$ & $\mathrm{X}$ & $\mathrm{X}$ & $\mathrm{X}$ & $\mathrm{X}$ & $\mathrm{X}$ & $\mathrm{X}$ & $\bar{X}$ \\
\hline
\end{tabular}

\section{B. Evolution to the Current State: The Case of Landsat}

Having introduced the key stakeholders in the US Remote Sensing Architecture, this section uses the evolutions of the Landsat program to illustrate the nature of their interactions. The system traces its origins to the start of the U.S. space program and the use of reconnaissance satellites. Civilian use of remote sensing kicked-off with NASA studying methods for remote sensing of earth resources from space through its Earth Resources Survey (ERS) program in 1965. A potential application of remote sensing data was also realized by the Department of Agriculture as it joined the program. The ERS program led to NASA's Earth Resources Technology Satellite (ERTS) project, later to be renamed Landsat. ${ }^{15}$ Although Landsat is just one of the remote sensing programs implemented over the last few decades, its origins and present state is representative of the organic evolution of the remote sensing industry in general.

The Landsat program's struggle for funding began even before it was initially approved. NASA had to demonstrate the practical applications of the data Landsat would gather in advance, in order to build support among its "customer" agencies. Deriving benefits from Landsat fell under the responsibilities of other agencies, such as the Department of the Interior and the Department of Agriculture. However, user agencies and organizations had their own needs and expectations and it was up to NASA to convince them that Landsat data could still be useful even if 
it did not fully meet their mission requirements. ${ }^{\text {xiv }}$ NASA was left "to force compromises before users had time to learn from experience with satellite data" ${ }^{16}$ It also required NASA to justify to the Bureau of the Budget (predecessor of Office of Management and Budget) the cost/benefit of the Landsat program replacing existing systems. Finally able to acquire the necessary funding to go ahead with the project, NASA launched Landsat in 1972.

The problems NASA encountered in gaining user support and funding for Landsat weakened its ability to respond to both $R \& D$ and operational needs. While research and development of satellite technology was familiar territory for the agency, managing cooperation with user agency and organizations was not. To help with the coordination process between NASA and future user agencies, several interagency committees ${ }^{\mathrm{xv}}$ were formed. However, they either mostly approved the decisions NASA had already made or were under NASA's general control. After the launch of Landsat 1 the project proved to be successful in delivering useful data to the scientific community; however, on the political side, questions were raised over the proper role of the government in further operating Landsat technology.

In 1979, the Carter Administration issued Presidential Directive 54, which transferred Landsat operation from NASA to NOAA and asked the Department of Commerce to look into ways of encouraging private sector participation in Landsat operation. The goal there was the "eventual operation by the private sector of our civil land remote sensing activities." " The commercialization of Landsat was complete when under President Reagan, Congress passed the Land Remote Sensing Commercialization Act of 1984 (P.L. 98-365). The Earth Observation Satellite Company (EOSAT), a joint venture of Hughes Aircraft and general Electric, was given the Landsat program. Under a 10-year contract, it would operate Landsat 4 and 5 and build Landsat 6 and 7.

Privatization, however, proved to be a failure. The government lowered its funding for commercialization and did not guarantee data purchasing. Various observations were missed because "there was no obvious and immediate buyer " ${ }^{, 18}$ while the price of Landsat imagery sharply increased. EOSAT's responsibility was then renegotiated to developing only Landsat 6. Recognizing its failure, Congress passed the Land Remote Sensing Policy Act of 1992, repealing the 1984 act on commercialization and retaking funding responsibility from the private sector. It designated the DOC to complete and launch Landsat 6, and NASA and DoD to develop and launch Landsat 7.

It was acknowledged that one of the greatest challenges of the future of environmental monitoring in the U.S. is the development of a coherent policy structure that balances both government and private data collection needs with US economic and security needs. Partly in response to this need, President Bush set forth a U.S. Commercial Remote Sensing Policy in 2003 to "advance and protect U.S. national security and foreign policy interests by maintaining the nation's leadership in remote sensing space activities, and by sustaining and enhancing U.S. remote sensing industry." 19 Through this policy, government use of commercially produced remote sensing data is encouraged while the U.S. government's focus will be on providing remote sensing systems that "cannot be effectively, affordably, and reliably satisfied by commercial providers" ${ }^{\text {vi }}$ This policy can be seen in action with the release of OSTP's 2007 “A Plan for a U.S. National Land Imaging Program”, for which USGS has received a budget line. It is but one step towards developing a plan of action for the US regarding the future of remote sensing. ${ }^{\text {xi }}$

In addition to introducing many of the key stakeholders in the remote sensing system - NASA, NOAA, DoD, USGS, USDA - this brief history highlights some of the key trade-offs that will be explored in more depth throughout the remainder of this report. Firstly, the primary users of space-based data do not have the expertise to collect it, or even operate the satellites. For example, where USGS was historically wholly responsible for all aspects of geological surveys, now with the advent of satellite imagery, USGS must rely on other government agencies (i.e., NASA, NOAA, DoD and at times commercial entities) to build and operate the satellites and provide them with the required data. This creates a coordination challenge, both in terms of the allocation of public resources and the hand-off of responsibility from one government agency to another. Secondly, while it is relatively well recognized that the government has no place managing a commercializable commodity, the failure to commercialize Landsat is illustrative of the difficulty in determining when a technology is sufficiently mature to be designated "operational/commercializable." While the failure can be partially attributed to an overestimation of the addressable market, an important reason for the lack of interest among commercial contractors stems from the enormous program risk associated with advanced satellite development.

${ }^{\text {xiv }}$ An example would be USDA expecting satellite data to replace aerial photography and thus wanting to collect fine resolution photographs. However, Landsat was limited by restrictions on resolution of photographs aimed to prevent any conclusions to be made over capabilities of classified satellites.

${ }^{x v}$ Earth Resource Survey Program Review Committee was formed in 1968 and replaced with the Interagency Coordinating Committee: Earth Resources Survey Program in 1972.

${ }^{x v i}$ The OSTP report only focuses on current problems and policy options for U.S. land imaging management. 


\section{Remote Sensing Value-Chain: The Nature of the "Hand-off" Challenge}

As discussed previously, the remote sensing system as a whole delivers value by generating and analyzing data, collected remotely by orbiting satellites. Much of the analysis constitutes leading edge science, using novel instruments. Thus, research and development of the enabling technology is an important precursor to deriving value from operational satellites. In fact, much of the recent discussion on challenges of the remote sensing system focuses on inefficiencies in the so-called hand-off between research and operational programs. This section takes a process view of the hand-off to better understand the nature of the dependencies.

\section{A. The Research to Operations Hand-off}

By its very nature, advanced science is, experimental and uncertain. It is impossible to know with certainty, $a$ priori, which measurements are i) attainable and ii) most useful. While all new data will increase our understanding of the earth system to some extent, given limited resources, prioritizing the most useful data to collect is clearly the goal. To determine the relative utility of a particular set of measurements requires experimentation on-orbit. This is accomplished using "technology demonstrators" which are short-design-life, proof-of-concept missions. In theory, if the tech demonstration mission proves "most useful", a follow-on operational mission will be approved (as illustrated in Figure 1). In reality, even for the few research missions that are taken up as operational follow-ons, the transition can take several years, creating significant gaps in data continuity.

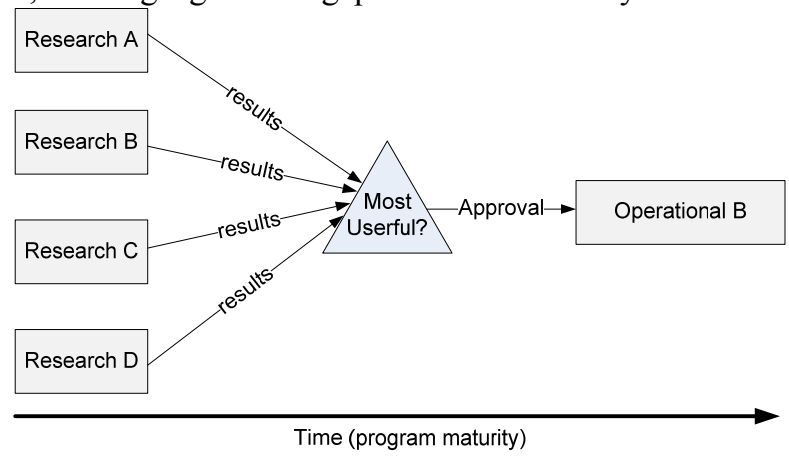

\section{Figure 1 - Notional down-selection from sever tech-demonstrator research missions to a follow-on operational mission based on demonstrated utility}

This handoff "gap" is often attributed to coordination challenges among the key stakeholders. Firstly, in part because NASA (the research organization) and NOAA (the operational organization) operate under separate budget authorities, it takes several years for a new operational program to be approved and developed even if it follows directly from a previous technology demonstrator program. This creates the gap in data continuity described above. Specifically, there is a lag between the time when the technology demonstrator is scheduled to be decommissioned after demonstrating its usefulness and the time when the follow-on satellite becomes operational. Second, despite being a mature concept, most follow-on satellites still require NASA's design, development and integration expertise to deliver them successfully to orbit. Thus, even after the handoff, NOAA typically contracts the development phase to NASA, limiting the practical significance of the RtoO handoff.

\section{B. Implicit Handoffs among Product Development Phases}

Implicit in the above discussion is a second dimension of the value-chain. In addition to the RtoO handoff in which a research organization (e.g., NASA) delivers a mature concept (as developed through a technology demonstrator satellite) to an operations organization (e.g., NOAA) which then initiates an operational program to generate data for the users; it considers the value chain within each satellite development. Specifically there are multiple handoffs from planning to R\&D and operations to use (i.e., planning delivers funding and specifications for a project; R\&D delivers an integrated satellite; operations delivers raw data; and users analyzes and archives said data). This concept is illustrated in Figure 2. In the figure, the x-axis measures calendar time. The labels on the $x$ axis indicate the start of the initial technology demonstrator (i.e., experimental) satellite and the follow-on satellite respectively. The y-axis progresses through the phases of a notional project lifecycle, from project approval through operations and finally data archiving. The trend lines show notional trajectories of each satellite mission in time and lifecycle phase. 
There are two main takeaways from Figure 2. First, it illustrates that the existence of a gap is inevitable. While poor coordination may lengthen the gap, part of the problem is intrinsic to the spacecraft development process. Specifically, if the need for an operational follow-on can't be accurately determined until the research mission has demonstrated its usefulness; the gap shown in red will always exist. The reality is that it takes time - several years to develop a follow-on satellite. A concrete example of this lag is illustrated in Figure 3. Improving coordination can minimize the gap, but eliminating it will require both an expedited assessment of the relative utility of the data collected during a tech demonstration and a streamlined approval process. Second, breaking out the dimension of within project handoffs provides an alternative way to conceptualize the division of labor. Rather than designating NASA a research agency and NOAA an operational agency, it may be more appropriate to consider NASA a designer, developer and launcher, NOAA an operator and USGS an analyzer and archiver. As alluded to above, many of these hand-offs happen already (e.g., NASA builds NOAA satellites, and USGS archives data for all) so it may present a framework that better mirrors the problem. This proposition will be explored extensively in the remainder of this report.

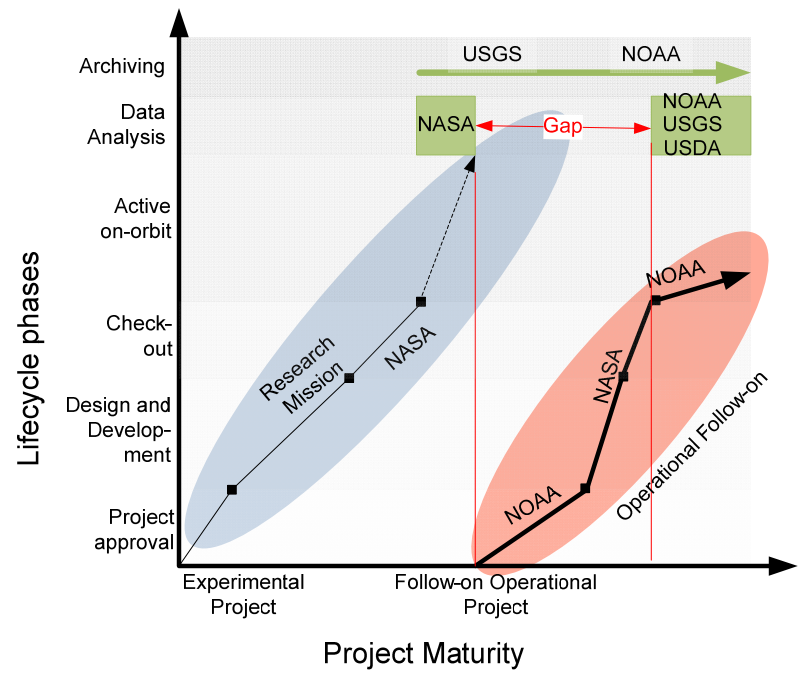

Figure 2 - Two ways to conceptualize the remote sensing value chain; the blue, coral, green areas indicate the roles nominally filled by NASA, NOAA and USGS respectively. The overlay of agency names on the plot, give a more accurate representation of the division of labor, discussed in more detail below.

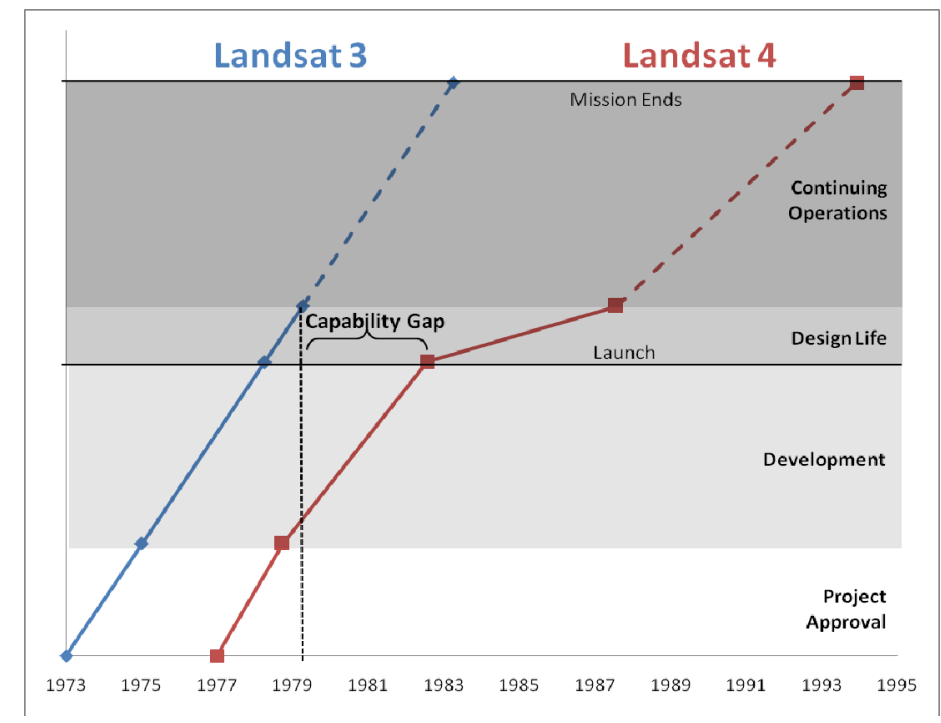

Figure 3 - The mission timeline of Landsat 3 and Landsat 4. Note the capability gap between the end of Landsat 3's design life and the launch of Landsat 4. This necessitated the continued operation of Landsat 3 until shortly after the launch of Landsat 4. 


\section{Remote Sensing Value Chain: Actual}

As illustrated through the stakeholder discussion in section II.0, the distribution of work across the value chain is far from clean cut. In fact, neither dimension of the value-chain conceptualization discussed above captures the division of labor within the current architecture. In an effort to identify the actual handoff sequence, organizational roles were mapped onto the baseline two-dimensional value-chain proposed in Figure 2. As summarized in Table 2 and described below, it was found that four parallel structures exist in the current remote sensing system.

Table 2 - Actual Remote Sensing System Division of Labor

\begin{tabular}{|c|c|c|c|c|}
\hline & \multicolumn{4}{|c|}{ Sub-architectures } \\
\hline & $\begin{array}{c}\text { Classified } \\
\text { Reconnaissance } \\
\end{array}$ & $\begin{array}{c}\text { Earth and Space } \\
\text { Weather Monitoring }\end{array}$ & Advanced Science & $\begin{array}{c}\text { Earth Imaging and } \\
\text { Mapping }\end{array}$ \\
\hline Planner & $\mathrm{DoD} / \mathrm{ClA}$ & NOAA & Sci $=>$ NASA & USGS \\
\hline Designer & NRO/Commercial & NASA/NOAA & NASA & NASA \\
\hline Developer & NRO/Commercial & NASA & NASA & NASA \\
\hline Launcher & NRO/Commercial & NASA & NASA & NASA \\
\hline Operator & $\mathrm{DoD}(\mathrm{NRO})$ & NOAA & $N A S A=>N O A A$ & NOAA \\
\hline Analyzer & $\mathrm{DoD}(\mathrm{NGA})$ & NOAA/DoD/Weather & Sci/NASA/USGS/USDA & NGA/USGS/USDA \\
\hline Archiver & DoD/CIA & NOAA & NASA/USGS & USGS \\
\hline
\end{tabular}

\section{Classified Reconnaissance}

The first type of remote sensing architecture is classified reconnaissance. Although handoffs occur among DoD agencies (planning is centralized and in collaboration with the CIA, the NRO designs, develops, launches and operates the asset, finally data is analyzed and archived by the NGA for the DoD-at-large and CIA) since all funding is apportioned from the DoD appropriation for satellite-based intelligence, no handoff gap need exist. Given the highly classified nature of these activities, the data necessary to comment on the effectiveness of leveraging commercial contracts (with DigitalGlobe and GeoEye) is not attainable.

\section{Earth and Space Weather Monitoring}

The second type of remote sensing architecture is weather monitoring. Having progressed to a sufficient level of technological and scientific maturity, weather satellites are operated by NOAA. As the lead agency, NOAA is responsible for analyzing, disseminating and archiving weather data, ${ }^{\text {xvii }}$ and oversees the operation of remote sensing assets. It "subcontracts" design, development and launch of the assets to NASA. Data from NOAA weather satellites are used by scientists and weather agencies among others. Since NOAA has budget authority over the planning, $R \& D$ and operations phases, one might expect clean handoffs; however, recent acquisition problems with GEOS-R and NPOESS, lend evidence to the contrary.

\section{Advanced Science}

The third remote sensing architecture is for advanced science missions, and it is dominated by NASA. NASA acts as a cradle-to-grave lead in the planning, design, development, launch, operations, analysis and archiving of data collected on these missions. Some advanced science missions, namely those with applications to weather monitoring or climate change, have in the past been transitioned to NOAA, recast as operational missions. Others, such as astrophysics and other non-Earth experiments, remain in a purely research capacity even as follow-on missions are developed. This creates problems because experimental science often requires the support of mature technology. Specifically, understanding new phenomena requires data to be collected over extended periods of time; yet, in the current set-up, experimental missions are short lived to prove out the technology. Thus, operational "advanced science" missions are needed in many areas.

\section{Earth Imaging as a Public Works Project in Space}

The fourth remote sensing architecture is for Earth imaging. As discussed in section II.0, mandates in the domain of earth imaging have evolved significantly. With the National Land Imaging Program, USGS retains responsibility for data analysis and archiving and gains a leadership role in requirements definition. NASA and NOAA continue to be involved with responsibility for design \& development and operations respectively. NGA and USDA (among other lesser users) also contribute in the area of data analysis and through the requirements process. It remains to be seen whether this new coordination model is effective. ${ }^{\text {xviii }}$

\footnotetext{
xvii On the military side, this role is shared by the Air Force SMC, although as discussed previously, SMC's role is diminishing.

${ }^{x v i i i}$ Compared to the management failures described in section 2.1 , it is hard to imagine this model not being an improvement.
} 


\section{Summary of Architectural Realities}

Nominally, all remote sensing programs are supposed to begin as experimental technology demonstrators. If the data collected by the demonstrators proves useful, the programs are supposed to be reconstituted as an operational follow-on. However, in reality, the above described transition seems to happen relatively infrequently; follow-ons to advanced science programs are still considered advanced science, under the purview of NASA; all weather monitoring satellites are perceived as operational, under the purview of NOAA; land imaging has become so routine that it is managed by the primary government user, USGS. If users were satisfied with the current system, one could argue that weather and land imaging are classes of satellites which have made the RtoO handoff, while advanced science is a name for classes of satellite which have not. However, they are not. Users of advanced science data need sustained programs to conduct their analysis, yet technology demonstrators have short operational lives. Weather satellites often employ experimental sensors and as a result, acquisitions have encountered cost and schedule issues, leading to unsatisfied users. And, despite being routine science, the commercialization of land imaging satellites was a massive failure. The roots of these issues are explored further in the section that follows.

\section{Analysis of Historical Remote Sensing Programs: A Winding Progression}

The previous sections have focused on the challenge of efficiently transitioning from research to operations. However, the concept of an RtoO handoff is predicated on a clear-cut classification of all missions as either "research" or "operational" and a unidirectional progression from the former to the latter. This section investigates the extent to which these two propositions are empirically valid, and discusses the implications of the findings for the RtoO handoff.

\section{A. Science vs. Technological Maturity: Conceptual Framework}

The proposition that NASA is a research agency while NOAA is an operations agency is somewhat misleading. Although NASA missions tend to tackle leading edge science questions, to do so effectively requires mature technical systems. Conversely, while weather science is relatively mature, the accuracy of instruments and the enabling technology continues to progress (i.e., it's conceivable to do mature science with experimental technology). The core idea here is that the RtoO progression incorporates at least two component dimensions - science and technology - as illustrated notionally in Figure 4.

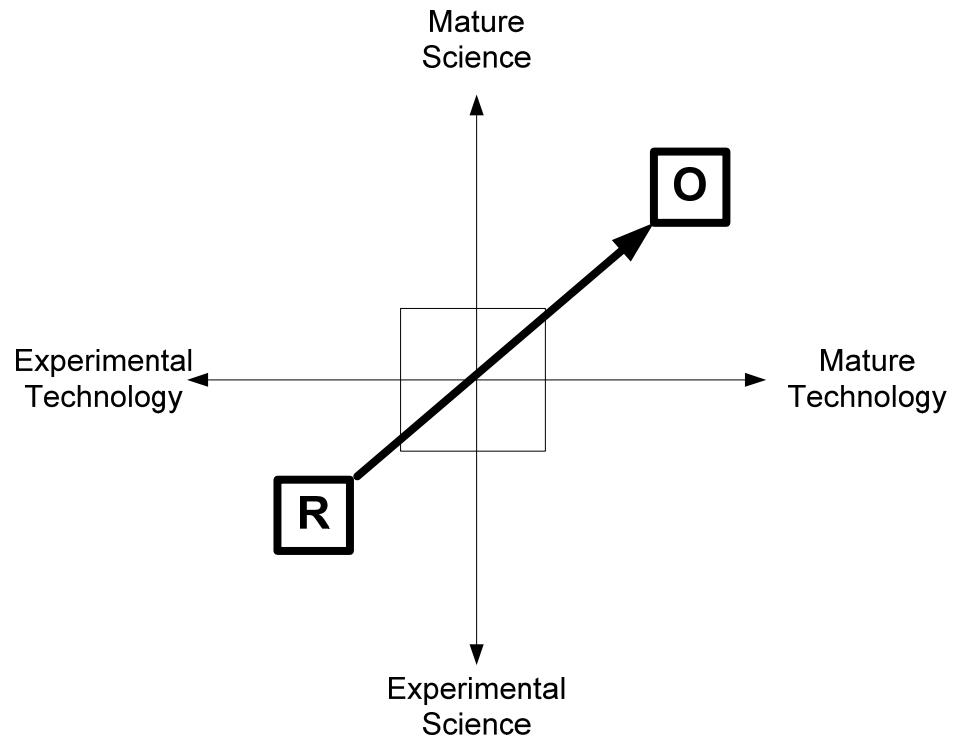

Figure 4 - Notional RtoO Progression

If in reality, programs progress along one axis at a time (e.g., from experimental technology/science to mature science/experimental technology and then to mature science/technology) then the system could conceivably be architected to better match the true progression. To explore this proposition, several historical sequences of remote sensing satellites were mapped onto Figure 4 notional framework. The result is Figure 5. 


\section{B. Science vs. Technological Maturity: Empirical Progression}

For the purposes of this discussion, both the scientific and technological continuum were discretized as follows. Along the scientific dimension, missions progress from most experimental to mature through the categories of: 1) measuring a phenomenon for the first time; 2) refining previously made observations; 3) both refining previous observations and extending the time baseline of the observations; finally 4) those missions that are launched solely to extend the time baseline of a set of observations. Along the technology dimension, missions progress through the categories of: 1) using new instruments that have been developed specifically for the mission; 2) instruments that are based on, or modifications of, previously flown instruments; 3) second in a series of follow-on missions; 4) third or higher in a series of follow-on missions. While there are surely other classification schemes along these dimensions, this one proved effective in differentiating between historical programs.

In order to understand the implications of Figure 5, it is instructive to highlight several satellite series independently. Consider first the GOES weather satellite sequence. Evolving on the "mature science" half of the spectrum, the series has been reconstituted several times (beginning with GOES 4, 8 and 13). Each time, the satellites returned to a relatively low level of technological maturity, although the science they were designed for was still mature. In such cases, should NOAA or NASA lead the development? Is it research or operations? Each new series had new instruments and enhanced capabilities as compared to the previous GOES spacecraft. As the first in their respective series, these three spacecraft were all built with experimental technology that required development projects on par with those conducted by NASA for its experimental science missions.

Now consider the A-Train sequence: launched in the order Aqua, Aura, CALIPSO and Cloudsat. ${ }^{\text {xix }}$ They follow a progression along the science maturity spectrum; however it is in the order of reverse maturity. This is not as contradictory as it sounds, since each satellite in the A-train is measuring a different phenomenon. The point is that given the broad range of science yet to be done, most advanced science missions are firsts in some respect. In the land imaging world, Landsats 1 to 3 did in fact follow the nominal research (experimental science/tech) to operations (mature science/tech) progression. However the remainder of the series cycled back through technical maturity spectrum. Ironically, it was as Landsat-3 regressed in maturity to Landsat-4 that the commercialization act was passed.

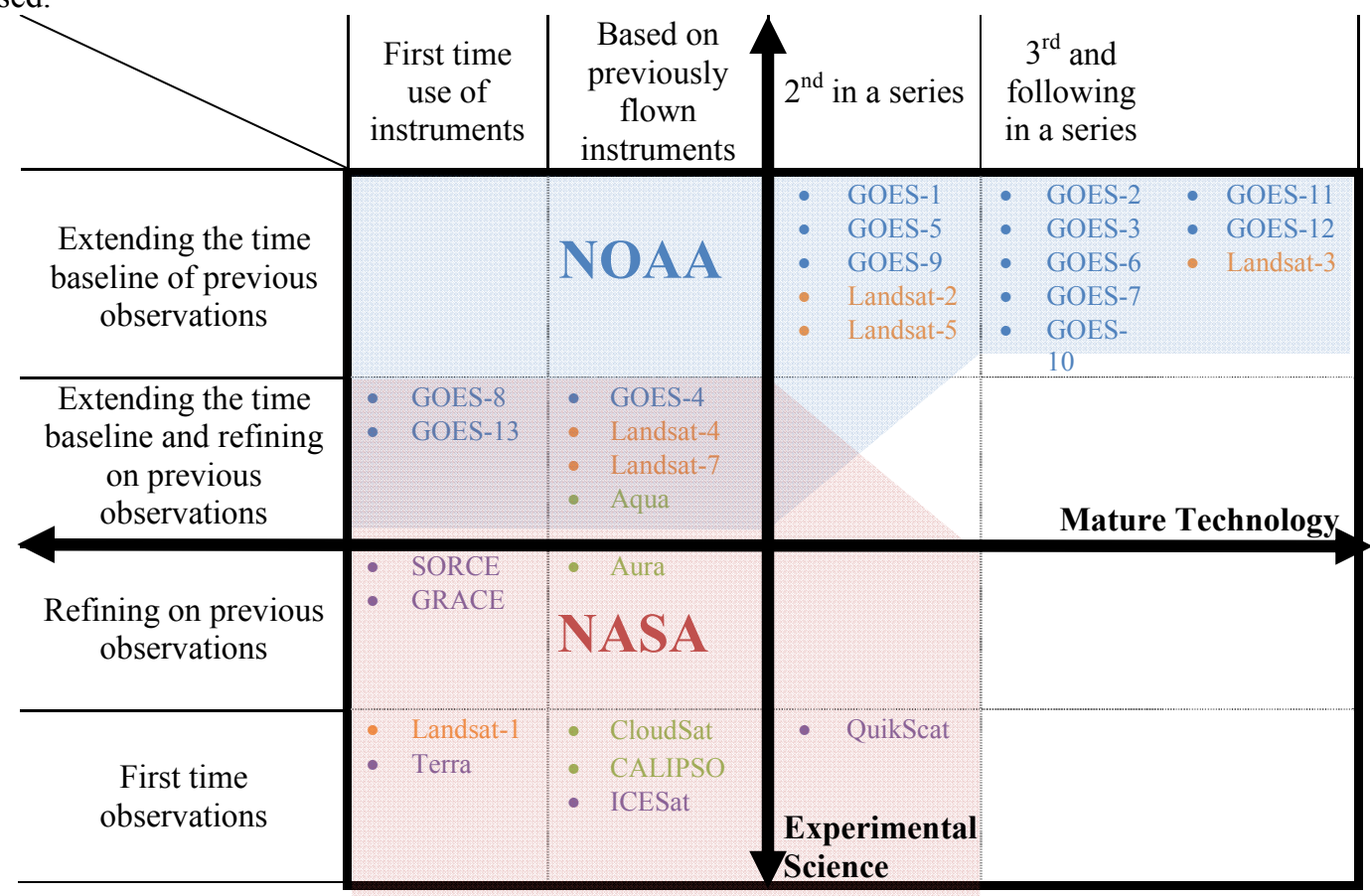

Figure 5 Different environmental monitoring missions organized according to their scientific and technological maturity. Included are the GOES satellites, the A Train constellation, the Landsat series, and satellites from NASA's Earth Observing System. The general regions covered by NASA and NOAA are also indicated.

${ }^{\text {xix }}$ OCO failed and the French-built PARASOL was launched in 2005. 
In addition to placing the satellite programs on the spectrum, Figure 5 illustrates the general regions covered by NASA and NOAA. The overlap in the agencies' regions in the figure is illustrative of their overlapping mandates in the field of environmental monitoring. Also it is noteworthy that except for the brief tenure of Landsat as a NOAA program, history suggests that operational is synonymous with weather. Whether or not weather is the most operational earth science, it seems clear that more than one technology demonstrator is required before a mission type is operational.

\section{Analysis of Alternative US Remote Sensing System Architectures}

In the previous sections, the current state of the US remote sensing system was described and analyzed. This section focuses on how this new understanding can be used to improve the system.

\section{A. US Remote Sensing System Architectural Alternatives}

The US remote sensing system is a system of organizations which themselves, design, develop, operate and use, systems. While it is "normal" to consider the design attributes of a physical system (i.e., the remote sensing satellite itself) it is less "normal" to think about designing systems of organizations. Nonetheless, the legal framework, budget authority and mandate etc under which agencies operate can have a strong impact on the way in which, and extent to which, the system achieves its goals. Assuming that government agencies will play a lead role in the remote sensing system for the foreseeable future, ${ }^{\mathrm{xx}}$ there are four standard approaches to restructure the interactions:

1. Remote Sensing Agency: Form a new remote sensing agency with authority over the entire remote sensing value chain (similar to the purview of the DoD in reconnaissance).

2. Consolidation of Roles: Give authority for the entire remote sensing value chain to a single existing agency. This is equivalent to option \#1 except that no new agency need be created.

3. Redefined Agency Roles: Clarify, and potentially alter, the roles and responsibilities of one, or more, of the existing agencies (i.e., NASA, USGS, NOAA, etc). This could serve to formalize current ad hoc practices (e.g., that NASA is NOAA's de facto spacecraft developer), or create a better alignment between agency expertise and natural phases of the mission lifecycles.

4. Inter-Agency Coordinating Body: From a new inter-agency coordinating body at the national level. It would draw members from all existing agencies. The goal would be to facilitate communication among the agencies and minimize hand-off delays.

\section{B. Analysis of Alternatives}

An initial glance at the architectural alternatives listed above reveals a trend from hardest to implement to easiest (from a political capital point of view). However, given the complexity of the challenges described in the previous sections, it is less clear which of the options would yield the most substantial improvement. This section assesses the extent to which each of the policy alternatives resolves the architectural challenges.

\section{Creation of a New "Remote Sensing Agency"}

From an effectiveness point of view, the new remote sensing agency option has a lot of potential. Centralizing funding for remote sensing activities under one agency, would give that agency the freedom to prioritize among the full portfolio of mission options (unlike in the current situation where, for example, NASA does not necessarily have the budget authority to continue operations on a particular mission). In addition, by centralizing authority and budget, the challenge of finding a distribution of work that fits the structure of the problem would be eliminated.

Precedence for creating a new agency to address a new problem can be found in the case of the creation of NASA in the 1950s. Most scholars agree that the NASA Act was successful; it created an agency dedicated exclusively to space and likely enabled the success of project Apollo. ${ }^{20}$ However, as a basis for assessing the new agency option in the context of remote sensing, there exist important differences to between NASA and the hypothetical "remote sensing agency" that are worth highlighting. Firstly, whereas space was a new enterprise in the 50 s, remote sensing is already a mature domain today. The question at hand is not where to develop a new set of competencies, rather how to organize existing competencies. Second, at the time of NASA's inception, space was an issue of primary policy. While satellite remote sensing can inform many of the central policy issues today, labeling remote sensing as a hot policy topic today would be significantly overstating matters.

Setting aside for a moment the practical reality that enacting a new agency requires an act of congress, to make the new agency viable, existing expertise, which are currently scattered across the multiplicity of agencies involved,

\footnotetext{
${ }^{x x}$ Given how ineffective the Remote Sensing Commercialization act of the 1990s was, this is a good assumption
} 
would either have to be centralized or duplicated. As a result, however the restructuring were to happen, several agencies would either be losing one of their core competencies, or find themselves contracting to another federal agency. Neither scenario will be readily accepted. Thus, while structurally speaking, this is the most efficient option, since it also requires the most political capital, it would be hardest to implement. The requisite political inertia likely does not exist at this time, but it may in the future.

\section{Consolidation}

If a natural candidate for consolidation of the environmental monitoring value chain under a single existing agency could be identified, this option offers many of the advantages of the new agency option, but requires less political capital. This approach is currently being implemented in the context of U.S. satellite land imaging through the consolidation of the lifecycle responsibility for Landsat under the USGS. The USGS was chosen for this role because it is both an important user of land images and boasts a long history managing "public works projects," albeit never previously in space. It is worth noting, that in the land imaging scenario, USGS will serve as a coordinating body with increased authority, but not complete budget authority. The other agencies in the National Land Imaging Program (NLIP) will continue to get direct appropriations for their portions of the project. It is too early to evaluate how successful this arrangement will be.

However, even if the NLIP proves wildly successful, this model cannot be ported directly to the broader remote sensing architecture. Where USGS is a natural choice for the leader of a land imaging program, there is no clear choice for remote sensing in general. None of the current government stakeholders have the range of expertise required to support, and make decisions about, the spectrum of remote sensing activities. As a result, consolidating responsibilities under any one agency would likely cause more problems than it would solve.

\section{Refined Agency Roles}

A third option for restructuring the organization of environmental monitoring efforts in the US is to refine (or clarify) the roles of the agencies already involved in environmental monitoring. One approach could be to better align their mandate with their expertise. As discussed in section III, although the hand-off is formally conceptualized as a transition from research to operations missions, in reality, agencies have evolved to specialize in aspects of the within-project value chain. For example, NASA is a technology developer and integrator; further, NOAA doesn't have hardware expertise, but has considerable experience interfacing with scientists and operating satellites. A potential way to partition the responsibilities is illustrated on the vertical axis of Figure 2.

The main advantage of this approach is that it leverages existing expertise and aligns well with the structure of the problem. It also requires less political capital than the previous options. However, dividing agency responsibilities in this way creates a whole set of new "handoffs" which present challenges in their own right. Most notably, unless project management responsibilities are assigned to someone (agency) one can imagine that coordination problems will result. Specifically, if budget authorities for NASA/NOAA/USGS continue to be appropriated through different committees, cost overruns in a particular part of the value chain may cripple the whole program.

A different division of labor might allocate agency responsibilities according to the types of problems being addressed. For example, NASA might become responsible for advanced science, both initial tech demonstrators and follow-on operational missions. While this would eliminate the multiple funding sources for each particular project, given the overlap of many remote sensing project types, this strategy would only serve to exacerbate the existing stovepipping and duplication of expertise/effort. Although neither of the above suggested restructuring strategies would mitigate current hand-off inefficiencies much, a goal of future work might be to investigate other alternative reorganizations which balance the need for oversight with a logical division of labor.

\section{Inter-Agency Coordinating Body}

A final alternative architecture option is the development of an inter-agency coordinating body to facilitate communication among existing parties. ${ }^{x x i}$ As a result, any USGEO-like body could only improve the status quo in so

\footnotetext{
${ }^{\mathrm{xxi}}$ A useful basis for understanding this option is USGEO. Constrained by the US Federal Advisory Committee Act, which requires that "unless otherwise specifically provided by statute or Presidential directive, advisory committees shall be utilized solely for advisory functions. Determinations of action to be taken and policy to be expressed with respect to matters upon which an advisory committee reports or makes recommendations shall be made solely by the President or an officer of the Federal Government."(US FACA Section 9(b)), the authority of such an advisory committee, and its ability to effectively manage inter-agency activity, is limited. As a result, any USGEO-like body could only improve the status quo in so far as it
} 
far as the observed hand-off challenges resulted from poor coordination among agencies, a coordinating body could go a long way to improve the situation. However, based on the analysis presented in section III, it appears that while poor communication may contribute to the problem, the root of the issue is structural. As shown in Figure 3, the time lag between so-called research and operational programs is an unavoidable consequence of the sequential organization of current environmental monitoring project development model. While the lag could likely be reduced through better coordination, it is unlikely that it could be eliminated. Elimination would require a restructuring of agency responsibilities as described above. That being said, a precursor to being able to define a suitable restructuring is the setting of clear overarching goals; something that a coordinating body can do effectively. This needs to be the focus of USGEO efforts. Once these goals are set, the other more aggressive reorganization strategies should be revisited.

\section{Summary and recommendations}

Having assessed the relative merits of the four standard restructuring approaches, it appears that short of creating a new agency with full authority over the remote sensing enterprise, none of the other strategies will improve the situation as framed herein. If it ever becomes feasible to create a centralized authority, that would be the cleanest solution. Until such a time, a reasonable near-term solution might be to investigate the feasibility of expanding NASA's mandate to include operational research missions (i.e., experimental science, mature technology) and NOAA's mandate to develop (or fund the development of) advanced technology for operational weather missions. While this approach would do nothing to remedy the duplication of effort currently in the system, it would ensure that the scientific community gets the data that they need. Later, depending on the success of NLIP the merits of consolidation should be revisited.

\section{Conclusion}

Weather satellites, and the broader category of environmental monitoring satellites for both terrestrial and space environments, have contributed immensely to our quality of life on earth. The accurate forecasting of terrestrial weather has improved agriculture, enhanced commerce in general, and saved numerous lives by providing advanced warning of natural disasters. In addition, the advanced warning of solar activity and the resulting disruption of earth orbit environments helps protect the satellites that provide this vital monitoring service. Yet the way the U.S. thinks about environmental monitoring - of both the terrestrial and orbital environments - from space is fragmented. The U.S. lacks a coherent integrated architecture, organization, and strategy for planning capabilities and investments in space-based environmental monitoring. Numerous government agencies, including NASA, NOAA, DoD, and the USGS are involved, but their roles and responsibilities are inconsistent and poorly defined. This has resulted in a limited ability to deliver consistent service to the user communities.

In order to clarify the problem, this paper provides way to conceptualize the capability development process in terms of a two dimensional value stream - within project development and between project developments. This framework is used to understand the challenges in the system in two ways. First, the roles and responsibilities of major stakeholders are overlaid on the conceptual representation to identify the actual organization of the system. Four system operating modes are identified: 1) Classified Reconnaissance; 2) Advanced Science; 3) Weather Monitoring; and 4) Land Imaging, each with a different division of labor. Despite limitations in each mode, they each provide insight into potential modifications to the overall process. Second, the nature of the observed inconsistent service delivery is investigated through an analysis of several historical projects. It is found that programs do not progress as expected from research to operations. Even when the progression is expanded to separate science maturity from technology maturity, many programs experience maturity cycles as major new generations are initiated.

By way of solution, four architectural alternatives were proposed and evaluated: 1) New Remote Sensing Agency; 2) Consolidation of Responsibilities; 3) Redefined Agency Roles; 4) Interagency Coordinating Body. Although the options offer increasing difficulty of implementation, they do not yield increased coherence of operation. This is because the complexities of the issues which underlie the handoff gap are not well addressed by standard architectural restructuring. However, if a division of labor which aligns better with current expertise and mandate could be found, a middle difficulty, middle impact could yield a strong positive improvement. The above described framework provides initial steps in this direction. However, until a coordinated vision for remote sensing is agreed to, it may be difficult to clarify agency roles. 


\section{References}

\footnotetext{
${ }^{1}$ GEOEye-1 Fact Sheet; URL: http://launch.geoeye.com/LaunchSite/about/fact sheet.aspx

${ }^{2}$ NASA (2009) "Earth - Science Mission Directorate" (in English); URL: http://nasascience.nasa.gov/earth-science

${ }^{3}$ NOAA, FY 2009 Blue Book (Budget Summary); URL:

http://www.corporateservices.noaa.gov/ nbo/09bluebook highlights.html

${ }^{4}$ US Department of the Interior, GPRA Strategic Plan Fiscal Year 2007-2012, Washington DC; URL: http://www.doi.gov/ppp/Strategic\%20Plan\%20FY07-12/strat plan fy2007 2012.pdf

${ }^{5}$ USGS Website: http://www.usgs.gov/aboutusgs/default.asp\#what

${ }^{6}$ U.S. Geological Survey, 2007, Facing tomorrow's challenges-U.S. Geological Survey science in the decade 2007-2017: U.S. Geological Survey Circular 1309, x +70 p.

${ }^{7}$ USDA Website: http://www.usda.gov/oce/remote sensing/coordination committee.htm

${ }^{8}$ Air Force Space Weather homepage: http://www.afweather.af.mil/units/spaceweatheroperations.asp

${ }^{9}$ Earth Observation Group homepage: http://www.ngdc.noaa.gov/dmsp/index.html

${ }^{10}$ National Reconnaissance Office Website: http://www.nro.gov/

${ }^{11}$ National Geospatial Intelligence Agency Website: https://www1.nga.mil/Pages/Default.aspx

${ }^{12}$ The Global Earth Observation System of Systems (GEOSS) 10-Year Implementation Plan (adopted 16 February 2005)

${ }^{13}$ GEO Website: http://earthobservations.org/index.html

${ }^{14}$ USGEO Charter; URL: http://usgeo.gov/docs/USGEO\%20charter.pdf

${ }^{15}$ Landsat Program Chronology; URL: http://geo.arc.nasa.gov/sge/landsat/lpchron.html

${ }^{16}$ Mack, P. (2006). LANDSAT and the Rise of Earth Resources Monitoring. P, Mack (Ed.), From Engineering Science to Big Science: The NACA and NASA Collier Trophy Research Project Winners (235-249). University Press of the Pacific

${ }^{17}$ Carter, James. "Civil Operational Remote Sensing." Presidential Directive 54 of November 16, 1979

${ }^{18}$ NASA Landsat 5; URL:http://landsat.gsfc.nasa.gov/about/landsat5.html

19 Bush, George W. "U.S. Commercial Remote Sensing Policy" of April 25, 2003 resulting from National Security Presidential Directive 15 of June 28, 2002

${ }^{20}$ Logsdon, John M., "The Decision to Go to the Moon: Project Apollo and the National Interest," MIT Press, Cambridge
} MA, 1970 